\title{
Temperature-sensitive $\beta$-Lactam-tolerant Mutants of Escherichia coli
}

\author{
By LAWRENCE C. SHIMMIN, $†$ DÉSIRÉE VANDERWEL, \\ ROBIN E. HARKNESS, BARBARA R. CURRIE, ANNE GALLOWAY \\ AND EDWARD E. ISHIGURO* \\ Department of Biochemistry and Microbiology, University of Victoria, Victoria, BC, \\ Canada V8W 2 Y2
}

(Received 30 December 1983)

\begin{abstract}
Seven temperature-sensitive penicillin-tolerant mutants of Escherichia coli strain LD5 (thi lys $A$ $d a p D$ ) were isolated and characterized. Treatment with $\beta$-lactams caused lysis of the mutants at $30^{\circ} \mathrm{C}$. Although growth of the mutants at $42^{\circ} \mathrm{C}$ was inhibited by $\beta$-lactams, no lysis occurred. The mutants were also slightly tolerant to $\mathrm{D}$-cycloserine at $42^{\circ} \mathrm{C}$ but lysed readily when deprived of diaminopimelate or when treated with moenomycin. The minimum inhibitory concentrations of various antibiotics were the same for the mutants and their parent. The mutations conferring penicillin tolerance were phenotypically suppressed in the presence of a variety of compounds which may act as chaotropic or antichaotropic agents. No defects in penicillin-binding proteins and peptidoglycan hydrolases were detected. Temperature-resistant revertants of the mutants were no longer tolerant to penicillin-induced autolysis at $42{ }^{\circ} \mathrm{C}$. The mutations in five isolates were localized to the 56 to $61 \mathrm{~min}$ region of the $E$. coli linkage map and to the 44 to $51 \mathrm{~min}$ region in the case of two other isolates.
\end{abstract}

\section{INTRODUCTION}

There are several peptidoglycan hydrolases associated with the cell envelope of Escherichia coli (Mirelman, 1979). The functions of these enzymes are unknown, but it has been speculated that they are involved in regulating peptidoglycan metabolism during growth and division. During normal growth, the activities of the peptidoglycan hydrolases are regulated such that the autolysis of cells apparently rarely occurs. However, treatments which interfere with peptidoglycan synthesis usually culminate in autolysis of $E$. coli, indicating that the peptidoglycan hydrolase activities become deregulated. Other bacterial species exhibit similar behaviour (Tomasz, 1979). In these cases, it is likely that the bactericidal effects of agents which inhibit peptidoglycan synthesis (e.g. $\beta$-lactam antibiotics) are attributable to autolysis. The mechanism by which the activities of the peptidoglycan hydrolases are regulated during normal growth is unknown. How the normal regulation of peptidoglycan hydrolases is interfered with when peptidoglycan synthesis is inhibited is also unknown.

Kitano \& Tomasz (1979a) have described mutants of $E$. coli which were tolerant to $\beta$-lactam antibiotics. Penicillin tolerance in one of their mutants was temperature-dependent and was expressed only at a high growth temperature $\left(42^{\circ} \mathrm{C}\right)$. The other mutants were designated as 'constitutive tolerant' (Kitano et al., 1980) because they were penicillin-tolerant at all growth temperatures. We describe here additional isolates of temperature-sensitive penicillin-tolerant mutants of $E$. coli and present the following new information on such mutants. (i) The mutations conferring penicillin tolerance were shown to be conditionally lethal. (ii) The mutations were

† Present address: Department of Biochemistry, University of British Columbia, Vancouver, BC, Canada V6T IW5.

Abbreviations: DAP, diaminopimelic acid; MTC, maximum tolerable concentration; PBP, penicillin-binding protein. 
phenotypically suppressed by a variety of compounds which may act as membrane perturbants. (iii) The mutations in five isolates were localized to the 56 to 61 min region of the E. coli linkage map and to the 44 to $51 \mathrm{~min}$ region in the case of two other isolates.

\section{METHODS}

Bacterial strains. Escherichia coli K12 strain LD5 (thi lysA dapD) has been described previously (Ishiguro \& Ramey, 1976). Strains VC32, VC44, VC49, VC51, VC52, VC53 and VC54 were temperature-sensitive penicillintolerant mutants derived from LD5. Temperature-resistant revertants of each of these mutants were isolated, and these were designated as strains VC321, VC441, VC491, VC511, VC521, VC531 and VC541, respectively. Strain KLF43/KL259 (thi tyrA pyrD his trp thyA recA mtl xyl malA galK rpsL $\mathrm{F}^{\prime} 143$ ) and strain KLF29/JC1553 (argG metB his leu recA mtl xyl malA gal lac $Y$ rpsL $F^{\prime} 129$ ) were from an $F^{\prime}$ strain kit obtained from Barbara $J$. Bachmann (E. coli Genetic Stock Center, Yale University).

Media and growth conditions. Except where indicated, bacteria were grown in Tryptic Soy broth (Difco) supplemented with $50 \mu \mathrm{g} \mathrm{DAP} \mathrm{ml}{ }^{-1}$ (TSB). A solid version of this medium, TSA, contained $1.5 \%(\mathrm{w} / \mathrm{v})$ agar. The minimal solid medium used was Davis minimal agar (Difco) with (ml-1) $2 \mathrm{mg}^{-1}$ glucose, $0.05 \mu \mathrm{g}$ thiamin, $50 \mu \mathrm{g} \mathrm{L}-$ lysine, and $10 \mu \mathrm{g}$ DAP. In a few experiments, the bacteria were grown in $\mathrm{M} 9$ minimal medium supplemented with the required growth factors as previously described (Ishiguro \& Ramey, 1976) using $0.2 \%$ glucose or $0.2 \%$ sodium succinate as the principal carbon-source. In designated cases, $0.2 \%$ Casamino acids (Difco) was added. Liquid cultures were grown at indicated temperatures in gyrotory waterbath shakers. The optical density of cultures was determined with a Klett-Summerson colorimeter using a green filter.

Isolation of mutants. Strain LD5 was mutagenized with ethyl methanesulphonate as described by Miller (1972) except that the survivors of the mutagenesis procedure were grown at $30^{\circ} \mathrm{C}$. The mutagenized culture was subjected to a two-or three-step procedure designed to enrich for temperature-sensitive $\beta$-lactam-tolerant mutants. In the first step, a culture of mutagenized cells was grown exponentially for three doublings at $30^{\circ} \mathrm{C}$ to a density of about $1 \times 10^{8}$ cells ml ${ }^{-1}$. The culture was then shifted to $42^{\circ} \mathrm{C}$. After $30 \mathrm{~min}$, either ampicillin $\left(50 \mu \mathrm{g} \mathrm{ml}^{-1}\right)$ or benzylpenicillin $\left(500 \mu \mathrm{g} \mathrm{ml}^{-1}\right)$ was added, and incubation was continued until the culture had lysed completely (as judged by no further decrease in turbidity). The surviving cells were collected by centrifugation, washed once with sterile saline, inoculated into fresh TSB, and allowed to grow to the end of the exponential growth phase at $30^{\circ} \mathrm{C}$. In the second step of the enrichment procedure, the survivors of the first enrichment were diluted into fresh medium, grown at $30^{\circ} \mathrm{C}$, and then shifted to $42^{\circ} \mathrm{C}$ as described above. After $30 \mathrm{~min}$ at $42{ }^{\circ} \mathrm{C}$, cephaloridine $\left(25 \mu \mathrm{g} \mathrm{ml}^{-1}\right)$ was added, and the culture was incubated until lysis was complete. The survivors were treated as described for the first step of the procedure. In the early phases of this study, a three-step enrichment procedure was used with the third step involving a repeat of the first step with either ampicillin or benzylpenicillin. Three of the mutants (strains VC32, VC44, and VC49) were isolated in this manner. It was subsequently found that $\beta$ lactam-tolerant mutants occurred at a higher frequency if the third step in the enrichment procedure was omitted. The other mutants selected for this study were isolated by the modified procedure.

The $\beta$-lactam-tolerant mutants were selected from the survivors of the enrichment procedure by a method similar to the one described by Kitano \& Tomasz (1979a). The cells were plated on TSA containing $500 \mu \mathrm{g}$ benzylpenicillin $\mathrm{ml}^{-1}$. The plates were incubated at $42^{\circ} \mathrm{C}$ for 12 to $18 \mathrm{~h}$. The colonies which appeared during this incubation period were apparently those of penicillin-resistant mutants and were not studied further. Each plate was then overlaid with $3 \mathrm{ml} 0.6 \%$ agar containing 800 units of penicillinase and incubation was continued at $30^{\circ} \mathrm{C}$ for 18 to $24 \mathrm{~h}$. The colonies which appeared after the addition of the penicillinase and during incubation at $30^{\circ} \mathrm{C}$ were picked, purified by streaking, and screened for $\beta$-lactam tolerance at $42^{\circ} \mathrm{C}$.

As discussed below, the $\beta$-lactam-tolerant mutants isolated by this method exhibited temperature-sensitive growth. Temperature-resistant revertants were isolated by plating the mutants on Davis minimal agar and picking colonies that grew at $42^{\circ} \mathrm{C}$.

Minimum inhibitory concentration (MIC). The MICs for the drugs used in this study were determined by preparing serial twofold dilutions of the drugs in TSB. Each tube was inoculated with the test strain to give an initial density of $1 \times 10^{5}$ cells $\mathrm{ml}^{-1}$. The presence or absence of growth in each tube was recorded after $16 \mathrm{~h}$ incubation at $30^{\circ} \mathrm{C}$.

Maximum tolerable concentration (MTC). The degree of tolerance to a $\beta$-lactam antibiotic was expressed as MTC, which was defined as the lowest concentration of the drug required to cause lysis at $42{ }^{\circ} \mathrm{C}$, i.e. at the nonpermissive temperature. To determine the MTC, a culture of the test strain was grown in TSB at $30^{\circ} \mathrm{C}$ to a density of about $1 \times 10^{8}$ cells ml$^{-1}$. The culture was then divided into $10 \mathrm{ml}$ portions. After 30 min incubation at $42{ }^{\circ} \mathrm{C}$, the test $\beta$-lactam antibiotic was added at various concentrations to the cultures. Autolysis was determined as a decrease in optical density. The MTC value was the lowest concentration which caused lysis within $120 \mathrm{~min}$.

Peptidoglycan hydrolase assays. Peptidoglycan hydrolases were activated in intact cells by treatment with $5 \%$ (w/v) trichloroacetic acid as described by Hartmann et al. (1974). The cells for this assay were labelled with $\left[{ }^{3} \mathrm{H}\right] \mathrm{DAP}$ as described below. A nonspecific assay for total peptidoglycan hydrolase activity in a cell-free extract 
using $\left[{ }^{3} \mathrm{H}\right] \mathrm{DAP}$-labelled peptidoglycan as a substrate was carried out by the method of Hartmann et al. (1972). The specific assays for peptidoglycan transglycosylase (Goodell \& Schwarz, 1977), $N$-acetylmuramyl-L-alanine amidase (van Heijenoort et al., 1975), endopeptidase (Hakenbeck et al., 1974), and D-alanine carboxypeptidase (Beck \& Park, 1976) have been described previously. The substrates for these assays were prepared from radioactive peptidoglycan obtained from strain $\mathrm{LD}$. The labelling of peptidoglycan was achieved by growing the bacteria in TSB containing $0.7 \mu \mathrm{Ci}\left[{ }^{3} \mathrm{H}\right] \mathrm{DAP} \mathrm{ml} l^{-1}\left(26 \mathrm{kBq} \mathrm{ml}^{-1}\right)$ or $0.02 \mu \mathrm{Ci}\left[{ }^{14} \mathrm{C}\right] \mathrm{DAP} \mathrm{ml}{ }^{-1}\left(0.74 \mathrm{kBq} \mathrm{m}^{-1}\right)$ as the sole source of DAP for 50 to $60 \mathrm{~min}$. The labelled peptidoglycan was prepared by boiling the cells in sodium dodecyl sulphate and collecting the insoluble fraction as previously described (Hartmann et al., 1972). The dimer substrate for the endopeptidase assay, labelled with $\left[{ }^{14} \mathrm{C}\right] \mathrm{DAP}$, was purified from lysozyme-digested peptidoglycan by the method of Primosigh et al. (1961).

Measurement of radioactivity. Radioactive samples on chromatography paper were counted in a toluene-based scintillation fluid (Ishiguro \& Ramey, 1976). Aqueous samples were counted in PCS solution (Amersham) diluted with xylene $(1: 1)$. All samples were counted with a Beckman LS-8100 liquid scintillation counter.

Penicillin-binding proteins. The activities of the pencillin-binding proteins were assayed at both $30^{\circ} \mathrm{C}$ and $42{ }^{\circ} \mathrm{C}$ by the method of Noguchi et al. (1979). The substrate for the assay was [G-3 $\left.{ }^{3} \mathrm{H}\right]$ benzylpenicillin $\left(56.9 \mathrm{mCi} \mathrm{ml}^{-1}\right.$; $2 \cdot 1 \mathrm{GBq} \mathrm{ml}^{-1}$ ), which was kindly provided by P. J. Cassidy (Merck, Sharp and Dohme Research Laboratories, Rahway, NJ, USA).

Protein determination. Protein concentrations were determined by the Lowry method as modified by Markwell $e t$ al. (1978).

$F^{\prime}$ complementation. A modification of a plate mating technique described by Miller (1972) was used for $F^{\prime}$ complementation. The $\mathrm{F}^{\prime}$ strains and the various mutants were grown as described except that incubation was at $30^{\circ} \mathrm{C}$. The recipients (i.e. the various mutant strains) were spread on Davis minimal agar plates (about $10^{7}$ cells per plate). Drops of the various $\mathrm{F}^{\prime}$ donors were deposited on segments of the recipient lawns. Plates with the recipients and the donors by themselves were prepared as controls. The plates were incubated at $42{ }^{\circ} \mathrm{C}$ and checked for complementation after 24 to $48 \mathrm{~h}$.

Materials. D-Cycloserine, $\beta$-lactam antibiotics, penicillinase, chloramphenicol, and amino acids were purchased from Sigma. Ethyl methanesulphonate was from Eastman Kodak. [ $\left.{ }^{3} \mathrm{H}\right] \mathrm{DAP}\left(50 \mathrm{Ci} \mathrm{mmol}{ }^{-1}, 1.85 \mathrm{TBq} \mathrm{mmol}^{-1}\right)$ and $\left[{ }^{14} \mathrm{C}\right] \mathrm{DAP}\left(332 \mathrm{mCi} \mathrm{mmol}^{-1}, 12 \mathrm{GBq} \mathrm{mmol}^{-1}\right)$ were obtained from Research Products International (Mount Prospect, Illinois) and Amersham, respectively. Uridine diphosphate- $N$-acetylmuramyl-pentapeptide labelled with ${ }^{14} \mathrm{C}$ at the terminal D-alanine position was synthesized as described previously (Beck \& Park, 1976). Moenomycin was the kind gift of Gerhard Huber (Hoechst Aktiengesellschaft, Frankfurt am Main, FRG).

\section{RESULTS}

The procedure used by Kitano \& Tomasz $(1979 a)$ for the isolation of penicillin-tolerant mutants was modified as described above to permit the selection of mutants which exhibited a temperature-dependent tolerance (i.e. at high temperatures only) to $\beta$-lactam antibiotics. The modification also took into account the possibility that a mutation conferring penicillin tolerance could be conditionally lethal. Indeed, all seven independent isolates obtained by this procedure were unable to form colonies at $42^{\circ} \mathrm{C}$. Furthermore, all seven mutants gave rise to spontaneous temperature-resistant revertants capable of colony formation at $42{ }^{\circ} \mathrm{C}$ at frequencies ranging from $2 \times 10^{-7}$ to $1 \times 10^{-9}$. All of the mutants exhibited a temperaturedependent tolerance to lysis induced by a variety of $\beta$-lactam antibiotics. For example, lysis of strain VC44 treated with benzylpenicillin occurred at $30^{\circ} \mathrm{C}$ but not at $42{ }^{\circ} \mathrm{C}$ (Fig. 1a). The growth rates of all of the mutants decreased markedly when cultures were shifted to $42{ }^{\circ} \mathrm{C}$. The temperature-resistant revertants of the mutants, e.g. strain VC441, were like the wild-type parent of the mutants, and were lysed by treatment with benzylpenicillin at both $30^{\circ} \mathrm{C}$ and at $42{ }^{\circ} \mathrm{C}$ (Fig. 1 b). The tolerance to penicillin-induced lysis at $42^{\circ} \mathrm{C}$ protected the mutants from the bactericidal effect of $\beta$-lactam antibiotics as illustrated in Fig. 2 with strains VC44 and VC441.

The mutants exhibited normal morphological characteristics under all growth conditions tested at both permissive and nonpermissive temperatures. However, all of the mutants grew poorly in comparison to their parent strain. Thus, we were concerned about the possibility that their penicillin-tolerant phenotypes were a direct consequence of their reduced growth rates at $42^{\circ} \mathrm{C}$. In an effort to discount this, the effect of reduced growth rates at $30^{\circ} \mathrm{C}$ on the sensitivity of the mutants to $\beta$-lactam antibiotics was determined. Similar results were obtained for all strains, and data for strain VC44 are shown in Fig. 3. Penicillin tolerance of VC44 was routinely demonstrated in TSB cultures growing at $42{ }^{\circ} \mathrm{C}$ with a doubling time of usually 80 min, but for 


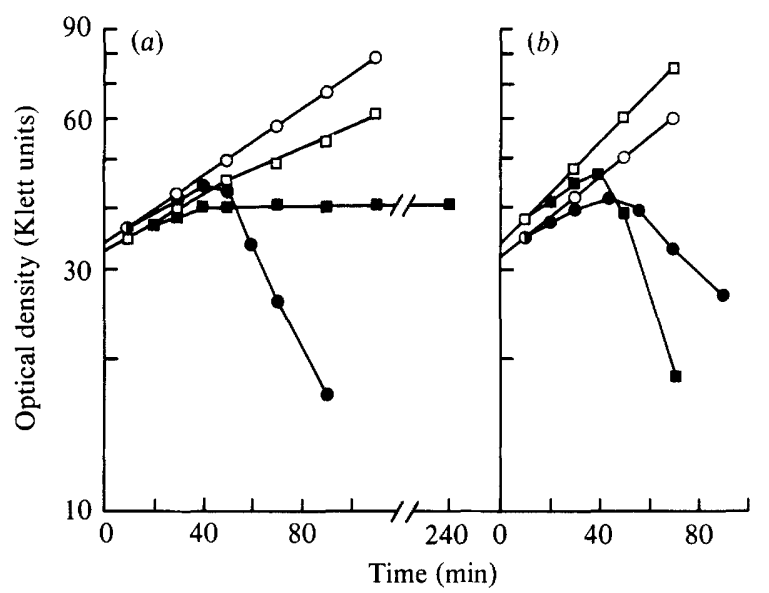

Fig. 1. Effect of benzylpenicillin on a penicillin-tolerant mutant, strain VC44 (a), and its temperatureresistant derivative, strain VC441 (b). Cultures growing at $30^{\circ} \mathrm{C}$ or at $42{ }^{\circ} \mathrm{C}$ were divided into two parts at $0 \mathrm{~min}$. Benzylpenicillin was added to one part at a final concentration of $500 \mu \mathrm{g} \mathrm{ml}^{-1}$, and the other part served as an untreated control. Open symbols, untreated control cultures at $30^{\circ} \mathrm{C}(\mathrm{O})$ and $42^{\circ} \mathrm{C}$ (口). Filled symbols, penicillin-treated cultures at $30^{\circ} \mathrm{C}(O)$ and $42^{\circ} \mathrm{C}(\mathbf{D})$.

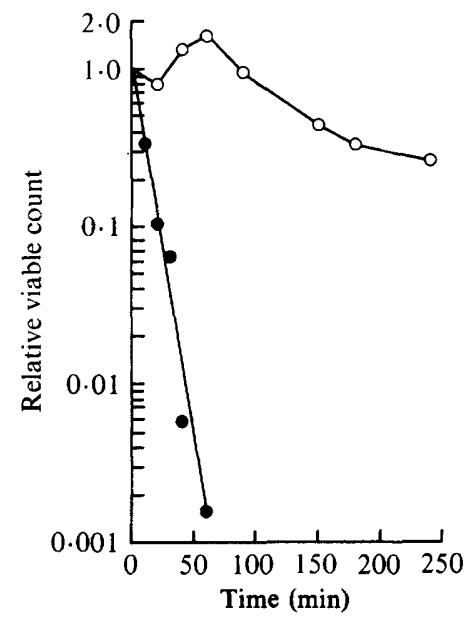

Fig. 2

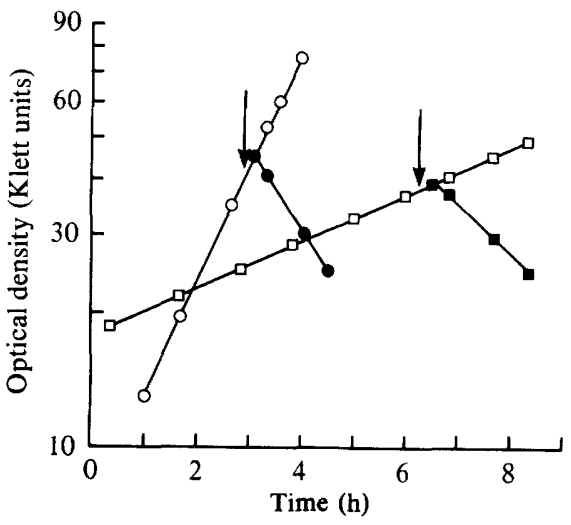

Fig. 3

Fig. 2. Effect of benzylpenicillin on viability of mutant strain VC44 (O) and revertant strain VC441 (O) at $42^{\circ} \mathrm{C}$. Benzylpenicillin $\left(500 \mu \mathrm{g} \mathrm{ml}^{-1}\right.$, final concentration) was added to cultures at $0 \mathrm{~min}$, and viable cell counts were determined at indicated times. A relative viable count value of 1 was equal to $1 \cdot 2$ $\times 10^{8}$ cells ml ${ }^{-1}$ for strain VC44 and $6.4 \times 10^{7}$ cells ml ${ }^{-1}$ for strain VC441.

Fig. 3. Effect of varying growth rates at $30^{\circ} \mathrm{C}$ on penicillin-induced lysis of strain VC44. Cultures were grown in glucose/M9 minimal medium with $0.2 \%$ Casamino acids $(O)$ and in succinate/M9 minimal medium ( $\square$ ). At the times indicated by the arrows, the cultures were divided into equal portions, and benzylpenicillin $\left(500 \mu \mathrm{g} \mathrm{ml}^{-1}\right.$, final concentration) was added to one portion $(O, \square)$.

unknown reasons, this was increased to about $90 \mathrm{~min}$ in a few cases. The doubling times at $30^{\circ} \mathrm{C}$ were varied over a wide range going from $65 \mathrm{~min}$ in glucose/M9/Casamino acids medium to $345 \mathrm{~min}$ in succinate/M9 minimal medium. Autolysis was induced by penicillin treatment in all cases, i.e. even at growth rates significantly lower than that used to demonstrate tolerance. This suggests that the tolerant phenotype was not growth rate-dependent. 
Table 1. MIC and MTC values for $\beta$-lactam antibiotics and D-cycloserine

MICs and MTCs are presented in terms of $\mu \mathrm{g} \mathrm{ml}^{-1}$. For benzylpenicillin and cephaloridine, the highest concentrations tested were 1000 and $800 \mu \mathrm{g} \mathrm{ml}^{-1}$, respectively.

\begin{tabular}{|c|c|c|c|c|c|c|c|c|}
\hline \multirow[b]{2}{*}{ Strain } & \multicolumn{2}{|c|}{ Benzylpenicillin } & \multicolumn{2}{|c|}{ Ampicillin } & \multicolumn{2}{|c|}{ Cephaloridine } & \multicolumn{2}{|c|}{ D-Cycloserine } \\
\hline & MIC & MTC & MIC & MTC & MIC & MTC & MIC & MTC \\
\hline LD5 & 50 & 50 & 5 & 5 & 6 & 6 & 10 & 10 \\
\hline VC32 & 50 & 1000 & 5 & 200 & 6 & 100 & 10 & 30 \\
\hline VC44 & 50 & 500 & 5 & 150 & 6 & 75 & 10 & 30 \\
\hline VC49 & 50 & 500 & 5 & 100 & 6 & 50 & 10 & 30 \\
\hline VC51 & 50 & $>1000$ & 5 & 300 & 6 & 300 & 10 & 20 \\
\hline VC52 & 50 & $>1000$ & 5 & 300 & 6 & 300 & 10 & 20 \\
\hline VC53 & 50 & $>1000$ & 5 & 300 & 6 & 400 & 10 & 20 \\
\hline VC54 & 50 & $>1000$ & 5 & 800 & 6 & $>800$ & 10 & 20 \\
\hline
\end{tabular}

The MICs of various $\beta$-lactam antibiotics were the same for the mutants and their wild-type parent. Interestingly, the temperature-dependent penicillin-tolerance could be overcome in many cases by treatment with very high concentrations of $\beta$-lactams at $42^{\circ} \mathrm{C}$. The minimum concentrations of $\beta$-lactams required to cause autolysis at $42{ }^{\circ} \mathrm{C}$, i.e. the MTCs, were determined, and Table 1 shows some representative results. Several points are noteworthy. (i) The MTCs for the mutants were generally at least tenfold higher than the MICs for the various $\beta$-lactams. (ii) The MTCs for the temperature-resistant revertants were similar to values obtained for the wild-type parent of the mutants, strain LD5 (data not shown). (iii) The MTCs for a given $\beta$-lactam varied from mutant to mutant. Thus, strains VC44 and VC49 exhibited relatively low degrees of tolerance to the $\beta$-lactams tested whereas strain VC54 was highly tolerant. The remainder of the mutants gave results intermediate to these two extremes. It is also noteworthy that all of the mutants were highly tolerant to benzylpenicillin, and four strains (VC51, VC52, VC53 and VC54) were apparently completely tolerant to this drug.

Table 1 also shows that the mutants were tolerant to $D$-cycloserine but to a significantly lesser extent than to $\beta$-lactams (MTCs of two to three times the MICs). On the other hand, all of the mutants lysed as rapidly as their parent when deprived of DAP at $42{ }^{\circ} \mathrm{C}$ and were not tolerant to moenomycin-induced lysis (data not shown).

Temperature downshift experiments indicated that the temperature-dependent tolerance to $\beta$-lactam-induced autolysis was reversible in all of the mutants and that protein synthesis was not required for reversal. For example, Fig. 4 shows that cultures of VC44 which were treated with benzylpenicillin at $42^{\circ} \mathrm{C}$ underwent autolysis shortly after a temperature downshift to $30^{\circ} \mathrm{C}$ even in the presence of chloramphenicol.

While searching for ways to suppress penicillin tolerance phenotypically, we found that a variety of compounds could induce lysis of the mutants treated with penicillin at $42^{\circ} \mathrm{C}$. The action of these compounds was concentration-dependent. For example, Fig. 5(a) shows that $0.1 \mathrm{M}-\mathrm{NaCl}$ had no effect on the tolerance of strain VC44 to benzylpenicillin at $42^{\circ} \mathrm{C}$, but $0.2 \mathrm{M}-$ and $0.4 \mathrm{M}-\mathrm{NaCl}$ caused lysis of the penicillin-treated cultures, the higher concentration apparently being more effective. Other active agents and their minimum effective concentrations were $\mathrm{NaSCN}, 0.1 \mathrm{M} ; \mathrm{NaI}, 0.2 \mathrm{M} ; \mathrm{NaClO}_{4}, 0.1 \mathrm{M} ; \mathrm{NaNO}_{3}, 0.4 \mathrm{M}$; and $\mathrm{Na}_{2} \mathrm{SO}_{4}$, $0 \cdot 1 \mathrm{M}$. Potassium salts worked equally well. Of the compounds tested, only sodium trichloroacetate (up to $0.4 \mathrm{M}$ ) and sucrose (up to $0.4 \mathrm{M}$ ) were ineffective. It is important to note that these compounds by themselves did not cause lysis of the mutants at $42^{\circ} \mathrm{C}$ under our experimental conditions; i.e. they caused lysis only if the mutants were treated with $\beta$-lactam drugs. Furthermore, high concentrations of these agents alone inhibited growth of the mutants. For example, Fig. $5(a)$ shows that $0 \cdot 1 \mathrm{M}-\mathrm{NaCl}$ had no effect on growth of $\mathrm{VC} 44$ at $42{ }^{\circ} \mathrm{C}$, but $0.2 \mathrm{M}$ - and $0.4 \mathrm{M}-\mathrm{NaCl}$ inhibited growth. As far as we could determine, these compounds had no effect on penicillin-induced lysis of the parent strain of these mutants; e.g. the compounds did not stimulate the rate of penicillin-induced lysis of strain LD5 at either $30^{\circ} \mathrm{C}$ or $42^{\circ} \mathrm{C}$. However, 


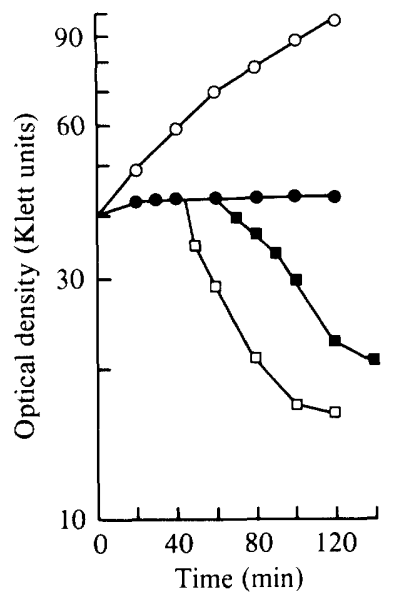

Fig. 4

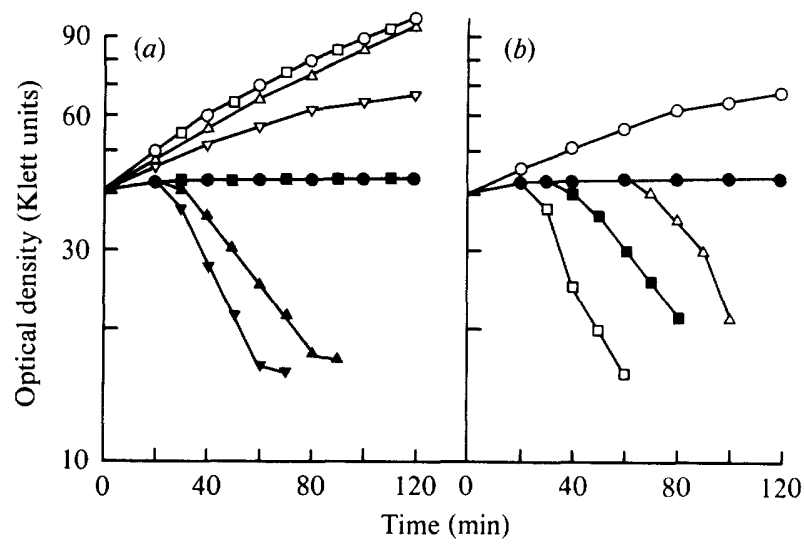

Fig. 5

Fig. 4. Effect of temperature-downshift on penicillin tolerance. Strain VC44 was grown at $42{ }^{\circ} \mathrm{C}$ with (O) and without $(O)$ benzylpenicillin $\left(500 \mu \mathrm{g} \mathrm{ml}^{-1}\right)$. Chloramphenicol $\left(200 \mu \mathrm{g} \mathrm{ml}^{-1}\right)$ was added to a portion of the penicillin-treated culture at $45 \mathrm{~min}$ and immediately transferred to $30^{\circ} \mathrm{C}(\square)$. Another portion of the penicillin-treated culture was transferred to $30^{\circ} \mathrm{C}$ at $60 \mathrm{~min}$ without chloramphenicol (a).

Fig. 5. Phenotypic suppression of penicillin tolerance in strain $\mathrm{VC} 44$ by $\mathrm{NaCl}$. (a) Concentration dependence. Strain VC44 was grown at $42^{\circ} \mathrm{C}$ without added $\mathrm{NaCl}(\mathrm{O}, \mathrm{O})$ and with $\mathrm{NaCl}$ at final concentrations of $0.1 \mathrm{M}(\square, \square), 0.2 \mathrm{M}(\triangle, \Delta)$, and $0.4 \mathrm{M}(\nabla, \nabla)$. Open symbols, no benzylpenicillin. Filled symbols, $500 \mu \mathrm{g}$ benzylpenicillin $\mathrm{ml}^{-1}$ added at $0 \mathrm{~min}$. (b) Effect of time of addition of $\mathrm{NaCl}$. Strain VC44 was treated with $500 \mu \mathrm{g}$ benzylpenicillin $\mathrm{ml}^{-1}$ at $42^{\circ} \mathrm{C}(\Theta) . \mathrm{NaCl}(0.4 \mathrm{M}$, final concentration) was added to portions of this culture at $0(\square), 30(\square)$, and $60(\triangle) \mathrm{min}$. $\bigcirc$, Control culture without benzylpenicillin and with $0.4 \mathrm{M}-\mathrm{NaCl}$.

the growth inhibitory effects of high concentrations of the compounds were also observed in strain LD5.

As shown in Fig. $5(a, b)$, when benzylpenicillin and $0.4 \mathrm{M}-\mathrm{NaCl}$ were added simultaneously to a culture of VC44 growing at $42^{\circ} \mathrm{C}$, lysis occurred about 30 min later. However, when $0.4 \mathrm{M}$ $\mathrm{NaCl}$ was added to a culture which had been treated with benzylpenicillin for at least $30 \mathrm{~min}$, lysis was initiated almost immediately (Fig. $5 b$ ). Identical results were obtained with the other agents. Thus, a period of at least $30 \mathrm{~min}$ of penicillin treatment was apparently required for the action of these phenotypic suppressors.

The peptidoglycan hydrolase activities of the mutants and their parent strain were compared by several methods. These included (i) determining the activities of the hydrolases which could be activated by treating intact cells with $5 \%$ trichloroacetic acid, (ii) assaying the total hydrolase activity in cell-free extracts using radioactive peptidoglycan as a substrate, and (iii) performing specific assays for $\mathrm{D}$-alanine carboxypeptidase, transglycosylase, endopeptidase, and muramyl$\mathrm{L}$-alanine amidase. For all of these procedures, the bacteria were grown at $30^{\circ} \mathrm{C}$ and at $42{ }^{\circ} \mathrm{C}$ (in the latter case, for $60 \mathrm{~min}$ ), and the hydrolases were assayed at $30^{\circ} \mathrm{C}$ and at $42^{\circ} \mathrm{C}$ for both sets of cells. No differences were found in the activities of the peptidoglycan hydrolases in the mutants and their parent strain by any of the above methods (data not shown). The PBPs of the mutants were also assayed in cells grown at $30^{\circ} \mathrm{C}$ or at $42^{\circ} \mathrm{C}$. The assays for each set of cells were performed at $30^{\circ} \mathrm{C}$ and at $42^{\circ} \mathrm{C}$ as for the peptidoglycan hydrolases. No abnormalities in the PBPs were detected (data not shown).

The mutations in all of the mutants were recessive and were localized by $\mathrm{F}^{\prime}$ complementation. The mutations in strains VC44 and VC49 were complemented by $F^{\prime} 129$ from strain KLF29/JC1553 and were therefore located in the 44 to 51 min region of the $E$. coli linkage map. The mutations in the other five mutants were complemented by $F^{\prime} 143$ from strain KLF43/KL259 indicating that the mutant loci were in the 56 to $61 \mathrm{~min}$ of the chromosome. No complementation occurred with $\mathrm{F}^{\prime}$ factors covering other regions of the chromosome. 


\section{DISCUSSION}

The mutants described here resembled one of the mutants described by Kitano \& Tomasz $(1979 a)$ in that penicillin tolerance was expressed only at high temperature. In retrospect, it is surprising that we did not encounter constitutive penicillin-tolerant mutants because: (i) these were apparently the more common type of penicillin-tolerant mutant (Kitano \& Tomasz, $1979 a$ ), and (ii) our selection procedure, although purposely designed for the isolation of temperature-sensitive mutants, should not have excluded constitutive mutants. The enhanced survival of our mutants during penicillin treatment at the nonpermissive temperature (Fig. 2) clearly confirms previous observations (Kitano \& Tomasz, 1979a) indicating that the lethal effect of $\beta$-lactams on $E$. coli is dependent on autolysis. The inability of our mutants to form colonies at high temperatures suggests that the mutant protein, apparently one required for the function of the autolytic enzyme system, was essential for normal growth. Furthermore, temperature-resistant revertants of the mutants regained wild-type characteristics, indicating that penicillin tolerance and temperature-sensitive growth were attributable to a single mutation. It is well known that $\beta$-lactams kill only actively growing bacteria, and it was possible that the penicillin tolerance of these mutants was due to their slow growth rates at $42{ }^{\circ} \mathrm{C}$. However, we feel this is unlikely since the mutants exhibited penicillin-induced autolysis at $30^{\circ} \mathrm{C}$ at growth rates which were much lower than those used at $42^{\circ} \mathrm{C}$ to demonstrate penicillin tolerance. The following observations are also noteworthy. (i) The mutation could be phenotypically suppressed by a variety of compounds. (ii) Tolerance to most $\beta$-lactams could be abolished by increasing the drug concentrations (Table 1); i.e. the mutants could be made to undergo penicillin-induced lysis at $42^{\circ} \mathrm{C}$ by high drug concentrations. These results clearly indicate that the mutants had the potential to lyse when treated with penicillin at $42^{\circ} \mathrm{C}$, and they provide a compelling argument against the idea that penicillin tolerance in these strains was a consequence of their poor growth characteristics.

The basis for the tolerance to penicillin-induced autolysis in our mutants is unknown. The constitutive penicillin-tolerant mutants described previously (Kitano et al., 1980) exhibited defects in both PBPs and peptidoglycan hydrolases. In contrast, no such defects were found in the temperature-sensitive penicillin-tolerant mutants in this study and in previous studies (Kitano \& Tomasz, 1979a; Kitano et al., 1980). On the other hand Kitano \& Tomasz (1979a) showed that penicillin treatment at $42^{\circ} \mathrm{C}$ failed to 'trigger' the autolytic enzyme system in their temperature-sensitive mutant. Thus, it is possible that the mutant protein in this case was involved in regulating the activity of peptidoglycan hydrolases. We were unable to test this since the autolysin triggering assay (Kitano \& Tomasz, 1979 b) does not work in strain LD5 and its mutant derivatives. The mutations in our mutants mapped in two regions of the $E$. coli chromosome indicating that the products of at least two genes were involved in penicillin tolerance. It is noteworthy that no PBPs are known to be encoded in these regions.

A variety of compounds phenotypically suppressed the temperature-sensitive mutations conferring penicillin tolerance. These agents caused autolysis only in cultures treated with $\beta$ lactam antibiotics. Furthermore, if the cultures were pretreated with penicillin for about $30 \mathrm{~min}$ at $42^{\circ} \mathrm{C}$, the addition of the agents resulted in almost immediate induction of autolysis (Fig. $5 \mathrm{~b}$ ). This may mean that, using Tomasz's (1979) terminology, the autolytic enzyme system was 'triggered' during the 30 min pretreatment period but autolysis did not occur because of the impaired function of the mutant protein. How the various compounds caused phenotypic suppression of the mutations is unknown, and the main difficulty here is that the mutant proteins have not been identified. Several possibilities are currently under investigation. Although the compounds may act by exerting an osmotic effect and perhaps somehow restoring the activity of the mutant protein, several observations suggest that this is not the mechanism. Firstly, sucrose was ineffective. Secondly, the active compounds did not restore colony formation in any of the mutants and therefore apparently did not restore the activity of the mutant protein. It is at least clear that these mutants were not of the temperature-sensitive osmotic-remedial type described previously by Egan \& Russell (1973). Alternatively, the action of the phenotypic suppressors may involve their known (Hatefi \& Hanstein, 1974) chaotropic or antichaotropic activities. However, in this case it is curious that both chaotropic and 
antichaotropic anions were effective since their activities are expected to be antagonistic. In a particularly relevant example, Ingram (1981) reported that chaotropic agents caused autolysis of actively growing $E$. coli by inhibiting the synthesis of crosslinked peptidoglycan and that antichaotropes blocked the action of the chaotropes. We are considering the possibility that perturbing the membrane with either a chaotrope or an antichaotrope resulted in the activation of the 'triggered' autolytic enzyme system (presumably membrane-bound) in the mutants. This may involve bypassing, rather than restoring, the function of the mutant protein. With respect to Ingram's (1981) report indicating that chaotropic anions mimic $\beta$-lactam antibiotics, it must be emphasized that autolysis did not occur in control cultures treated with any of the active compounds by themselves under our experimental conditions (Fig. 4).

Kitano \& Tomasz $(1979 a)$ reported that their temperature-sensitive mutant was specifically tolerant to $\beta$-lactams and lysed when treated with D-cycloserine and fluoro-D-alanine or when deprived of DAP. We obtained the same results with our isolates except that we detected a slight tolerance to D-cycloserine in all of the mutants. This may mean that the autolysins or the general mechanisms involved in lysis induced by DAP deprivation, and possibly by agents which inhibit early steps in peptidoglycan synthesis (e.g. D-cycloserine), may be different from those causing penicillin-induced lysis. However, at least one common component must be involved in these various lytic processes, since we (Harkness \& Ishiguro, 1983) have also isolated temperaturesensitive autolysis-defective mutants which exhibited a temperature-dependent tolerance not only to penicillin-induced lysis but also to all other lysis-inducing conditions tested (e.g. treatment with D-cycloserine or moenomycin and DAP deprivation). These autolysis-defective mutants also differed from the penicillin-tolerant mutants described in this paper in at least two other properties. Firstly, we have been unable to phenotypically suppress these mutations. Secondly, tolerance to lysis in these mutants could not be overcome even with saturating concentrations of drugs. With respect to the latter characteristic, it is interesting that penicillin tolerance in all of the mutants described to date (Kitano \& Tomasz, $1979 a$; this paper) could often be overcome by high concentrations of $\beta$-lactams. This property is reminiscent of $K_{\mathrm{m}}$ mutants in which the mutant proteins exhibit a decreased affinity for its substrate, but this may not be the mechanism here since we were unable to implicate a PBP defect in our mutants.

This work was supported by an Undergraduate Summer Research Fellowship (to A. G.) and by Operating Grant A6731 (to E. E. I.), both from the Natural Sciences and Engineering Research Council of Canada.

We thank Barbara J. Bachmann for bacterial strains, Patrick J. Cassidy for the $\left[{ }^{3} \mathrm{H}\right]$ penicillin, and Gerhard Huber for the moenomycin.

\section{REFERENCES}

BECK, B. C. \& PARK, J. T. (1976). Activity of three murein hydrolases during the cell division of Escherichia coli $\mathrm{K}-12$ as measured in toluene-treated cells. Journal of Bacteriology 126, 1250-1260.

Egan, A. F. \& Russell, R. R. B. (1973). Conditional mutations affecting the cell envelope of Escherichia coli K-12. Genetical Research 21, 139-152.

GOODELl, E. W. \& Schwarz, U. (1977). Enzymes synthesizing and hydrolysing murein in Escherichia coli. Topographical distribution over the cell envelope. European Journal of Biochemistry 81, 205-210.

Hakenbeck, R., Goodell, E. W. \& Schwarz, U. (1974). Compartmentalization of murein hydrolases in the envelope of Escherichia coli. FEBS Letters $\mathbf{4 0}$, 261-264.

HARKNESS, R. E. \& Ishiguro, E. E. (1983). Temperature-sensitive autolysis-defective mutants of Escherichia coli. Journal of Bacteriology 155, 15-21.

Hartmann, R., HöltJe, J. V. \& Schwarz, U. (1972). Targets of penicillin action in Escherichia coli. Nature, London 235, 426-429.
Hartmann, R., Bock-Hennig, S. B. \& Schwarz, U. (1974). Murein hydrolases in the envelope of Escherichia coli. Properties in situ and solubilization from the envelope. European Journal of Biochemistry 41, 203-208.

Hatefi, Y. \& HANSTEIN, W. G. (1974). Destabilization of membranes with chaotropic ions. Methods in Enzymology 31, 770-790.

van Heijenoort, J., Parquet, C., Flouret, B. \& van HEIJENOORT, Y. (1975). Envelope-bound $N$-acetylmuramyl-L-alanine amidase of Escherichia coli K-12. European Journal of Biochemistry 58, 611-619.

INGRAM, L. O. (1981). Mechanism of lysis of Escherichia coli by ethanol and other chaotropic agents. Journal of Bacteriology 146, 331-336.

IshIGURo, E. E. \& RAMEY, W. D. (1976). Stringent control of peptidoglycan biosynthesis in Escherichia coli K-12. Journal of Bacteriology 127, 1119-1126.

KItANO, K. \& Tomasz, A. (1979a). Escherichia coli mutants tolerant to beta lactam antibiotics. Journal of Bacteriology 140, 955-963. 
Kitano, K. \& Tomasz, A. (1979b). Triggering of autolytic cell wall degradation in Escherichia coli by beta-lactam antibiotics. Antimicrobial Agents and Chemotherapy 16, 838-848.

Kitano, K., Williamson, R. \& Tomasz, A. (1980). Murein hydrolase defect in beta lactam tolerant mutants of Escherichia coli. FEMS Microbiology Letters 7, 133-136.

Markwell, M. A. K., HaAs, S. M., Bieber, L. L. \& TOLBERT, N. E. (1978). A modification of the Lowry procedure to simplify protein determination in membrane and lipoprotein samples. Analytical Biochemistry 87, 206-210.

MILLER, J. H. (1972). Experimental Molecular Genetics. New York: Cold Spring Harbor Laboratory.

MirelmaN, D. (1979). Biosynthesis and assembly of cell wall peptidoglycan. In Bacterial Outer Membranes. Biogenesis and Functions. pp. 115-166. Edited by M. Inouye. New York: John Wiley \& Sons.

Noguchi, H., Matsuhashi, M. \& Mitsuhashi, S. (1979). Comparative studies of penicillin-binding proteins in Pseudomonas aeruginosa and Escherichia coli. European Journal of Biochemistry 100, 41-49.

Primosigh, J., Pelzer, H., MaAs, D. \& Weidel, W. (1961). Chemical characterization of mucopeptides released from the $E$. coli B cell wall by enzymic action. Biochimica et biophysica acta 46, 68-80.

TOMASz, A. (1979). The mechanism of the irreversible antimicrobial effects of penicillins: how the betalactam antibiotics kill and lyse bacteria. Annual Review of Microbiology 33, 113-137. 